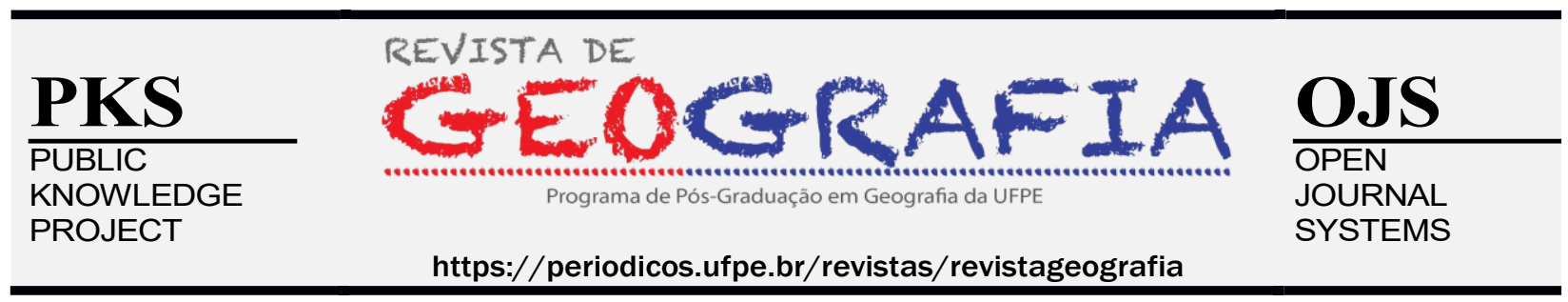

\title{
FLUXOS E FOMES: CORRELAÇÕES ENTRE DINÂMICAS AGRÍCOLAS E SEGURANÇA ALIMENTAR NA ECONOMIA MUNDO DO SÉCULO XXI
}

\author{
Ângelo Belletti ${ }^{1}$ \\ ${ }^{1}$ Universidade Federal do Rio Grande do Sul (UFRGS/PGDR), Historiador (UFRGS), Especialista em Agronegócio \\ (ESALQ/USP), Mestrando em Desenvolvimento Rural (PGDR/UFRGS).E-mail: angelo.belletti@hotmail.com, Orcid: \\ http://orcid.org/0000-0002-3003-1401
}

Artigo recebido em 06/08/2021 e aceito em 18/09/2021

\begin{abstract}
RESUMO
Em um período de fortes crises socioeconômicas globais, novamente a fome volta a ter merecido destaque nos debates públicos. Nessa direção, o artigo utiliza das contribuições internacionalistas sobre Sistema Mundo e Regimes Alimentares para pensar a subnutrição enquanto relacionada as práticas econômicas globais. Para tal, faz-se uso de análises quantitativas de dados relativos à produção agrícola e nutrição da população em diferentes realidades nacionais. Com as mesmas, constrói-se uma tipologia dos quadros nacionais em relação a produção agrícola e a garantia da segurança alimentar local. $\mathrm{O}$ artigo utiliza amostragem de tantos países quanto possíveis, a fim de construir um quadro amplo. Como resultado foram encontradas correlações inversas entre produção agrícola e segurança alimentar, indicando não haver uma reciprocidade entre maior produção e alimentação. Também foi verificada a validade da leitura das situações nacionais através dos conceitos de periferia, semi periferia e centro da dinâmica capitalista. Por fim, destaca-se outras perspectivas produtivas e alternativas sistêmicas ao modo de produção contemporâneo convencional.
\end{abstract}

Palavras Chave: Alimentação; Regimes Alimentares; Commodities; Desenvolvimento Rural; Fome.

\section{FLOWS AND HUNGER: CORRELATIONS BETWEEN AGRICULTURAL DYNAMICS AND FOOD SECURITY IN THE WORLD ECONOMY OF $21^{\mathrm{TH}}$ CENTURY}

\begin{abstract}
In a time of a strong global socioeconomic crises, hunger comes to a deserved central point in public discussions. In this direction, the article uses internationalists theories, such as World System and Food Regimes to approach sub-nutrition as a point related to the global economical practices. To do so, quantitative analyses are applied in data related to agricultural production and nutritional indicators over different countries. Through the correlation of these data, a typology of different national situations was built. There were used as much countries as the possible considering the available data aiming to establish the widest possible screen. As a result, negative correlations were found between agricultural production and food security, indicating that there is not a reciprocity between a higher production level and nutrition of the population. Also were verified the applicability of the concepts of center, periphery and semi
\end{abstract}


periphery as accountable of capitalist dynamic. At the end, there were also presented systemic alternatives to think our contemporary productive system.

Keywords: Food; Food Regimes; Commodities; Rural Development; Hunger.

\section{FLUJOS Y HAMBRE: CORRELACIONES ENTRE DINÁMICAS AGRÍCOLAS Y SEGURIDAD ALIMENTARIA EN LA ECONOMÍA MUNDO DEL SIGLO VEINTIUNO}

\section{RESUMEN}

En un periodo de fuerte crisis socio económica global, el hambre vuelve a tener un merecido espacio central en las discusiones publicas. En esa dirección, el articulo utiliza contribuciones de teorías internacionalistas, como Sistema Mundo y Regímenes Alimenticios, para trabajar la malnutrición como relacionada a las platicas económicas globales. Para tal, hace uso de análisis cuantitativas de datos acerca a la producción agrícola e nutrición de las poblaciones en diferentes países. A través de observación de correlaciones, una tipología fue construida de las realidades nacionales en relación a su producción agrícola y nutriciones. Fueran utilizados todos los países que tenían de datos en las bases utilizadas visando crear un cuadro mas amplio. Como resultado fueran encontradas correlaciones negativas entre la producción agrícola y la seguridad alimentaria, apuntando para una realidad donde no hay reciprocidad entre mayor producción y alimentación. También fue verificada la validad de la lectura de situaciones nacionales a través de los conceptos de periferia, semi periferia y centro de la dinámica capitalista. Al fin, otras perspectivas productivas y alternativas sistémicas para el modos de producción contemporáneo fueran trabajadas.

Palabras clave: Alimentación; Regímenes Alimentares; Commodities; Desarrollo Rural; Hambre.

Floema e xilema são estruturas centrais na sustentação das plantas. É através dessas que água, nutrientes e oxigênio circularão pelo corpo vegetal. A especifidade desses fluxos é essencial para a determinação das diferentes espécies. O milho, por exemplo, terá um quadro próprio dos seus elementos para conformar aquilo que entende-se enquanto milho. Entretanto, não somente através de estruturas biológicas se lê um organismo, o mesmo também é carregado em fatores sociais. O milho foi, e é, cultivado por comunidades andinas há aproximadamente quatro mil anos. Serviu de elemento ritualístico, base para objetos cotidianos e como alimentação. Todavia, com o mesmo compasso de floema e xilema, o milho cotidiano encontrado nos centros urbanos da sociedade ocidental não carrega nenhum desses elementos consigo. Apesar de milho ser sempre milho, entre o maiz altiplano e o corn estadunidense existem diferenças significativas. Um dos elementos dessa distinção é a construção social elaborada sobre as diferentes formas de milho (FRIEDMANN, 1999). Enquanto o maiz é fruto de uma dinâmica social, o corn é fruto de uma outra.

E é essa segunda sociabilidade que caracteriza e afeta os fluxos alimentares contemporâneos e, logo, necessária de ser continuamente destrinchada a fim de ampliar a compreensão sobre a relação entre seres humanos e o acesso à alimentação. A essencialidade do debate sobre o tema emerge em um momento no qual a segurança alimentar da população global é profundamente tensionada pelos efeitos decorrentes da pandemia de coronavírus e das práticas ineficientes de 
diferentes governos globais em garantir direitos mínimos da população. O caso brasileiro, por exemplo, é bastante emblemático nesse aspecto ao haverem 116,8 milhões de pessoas em situação de algum nível de insegurança alimentar no país ${ }^{1}$, ao mesmo tempo que este detém posições de liderança em diferentes produções agrícolas.

Se, mesmo com uma alta efetividade agronômica, um país não garante a disponibilidade alimentar interna, para onde direcionam-se as produções agroalimentares?

É na tentativa de responder a esse questionamento, bem como caracterizar os fluxos alimentares da estrutura global que o presente artigo se debruça. E, ainda, pensar quais outros traçados possíveis podem ser exercitados visando a garantia do direito a alimentação e promoção dos Objetivos de Desenvolvimento Sustentável - em especial o Objetivo 2 para Fome Zero e Agricultura Sustentável e Objetivo 12 para Consumo e Produção Responsáveis.

Para tal, serão utilizados três eixos de debate.

O primeiro é a leitura das relações internacionais a partir da teoria do Sistema Mundo e de outras contribuições para o debate socioeconômico, histórico e internacionalista, principalmente desde uma perspectiva histórico dialética e institucionalista. Parte dessa seleção bibliográfica a primeira hipótese do trabalho em entender que há diferenças nas produções globais, havendo a possibilidade de apontar níveis de produção agrícola e divisão internacional do trabalho. Uma outra hipótese, e ainda neste tópico, pauta-se nas contribuições relacionadas aos Regimes Alimentares, em especial a premissa proposta por Philip McMichael (2016) de que, na estrutura agrícola contemporânea, os agroalimentos são imbuídas em valor de troca, para somente depois serem considerados enquanto valor de uso. Ou seja, alimentos que são primeiro fluxo de capital, para somente então, serem de fato alimentos.

No segundo eixo, será feita a análise de dados quantitativos levantados pela Food and Agriculture Organization (FAO/ONU) e pelo Banco Mundial a fim de traçar características gerais dos fluxos agrícolas globais. Esse processo será trabalhado em três momentos, quais sejam: (i) relação entre valor total produzido e participação agroalimentar na composição dos produtos internos nacionais; (ii) valores indicativos de segurança alimentar, em suas diferentes dimensões, bem como de consumo proteico diário; e (iii) correlação das informações quantitativas a fim de analisar os efeitos entre valores de produção agroalimentar e garantia alimentar da população dos países. Cabe salientar que os elementos trabalhados são restritos a temporalidade do século XXI e foram sistematizados de acordo com a melhor visualização dos dados e disponibilidade dos mesmos.

1 Dados levantados pelo VIGISAN e disponíveis em: <olheparaafome.com.br> (acesso em 15/04/2021). 
Através da construção de correlações dos dados quantitativos, será construída uma tipologia da condição dos países em relação a sua manutenção nutricional alimentar interna frente sua produção (MARRADI, 1990). Para a construção das tipologias serão utilizadas, também, as trajetórias históricas nacionais, retomando as concepções de periferia, semi periferia e centro do Sistema Mundo (WALLERSTEIN, 2004).

Por fim, no terceiro eixo, serão trazidos argumentos ao debate sobre cadeias alimentares e as possibilidades de reconfiguração das mesmas visando uma distribuição equitativa e a garantia de segurança alimentar das populações.

Como resultado, foram levantadas informações que indicam não haver, necessariamente, uma reciprocidade entre valor agrícola total produzido pelos países no século XXI e garantia de segurança alimentar da população local. Entretanto, países com uma alta participação da agricultura no PIB apresentaram correlação com menores índices alimentares, apontando que economias predominantemente agrícolas apresentam situações nutricionais instáveis frente a composição global. Também foi possível identificar efetividade da teoria do Sistema Mundo em perceber as divisões dos países na estrutura global, visto ser relacionar a tipologia construída com a interpretação de economias centrais, semi periféricas e periféricas.

Além da presente introdução, o artigo conta com três subtítulos, um para cada tópico supracitado, bem como uma derradeira subdivisão para considerações finais e demais apontamentos.

\section{Expansão do capitalismo, sistema mundo e regimes alimentares}

O capitalismo emergiu enquanto um fenômeno europeu que se disseminou ao longo do globo (BRAUDEL, 1987). Diferentes autores trabalharam em interpretar os motivadores dessa expansão. Como amostragem desses disparadores, por mais que por vezes contraditórias entre si, os trabalhos clássicos de Nikolai Bukharin (1976), Karl Kautsky (1914) e Rosa Luxemburgo (1976) trouxeram fatores centrais para pensar os fluxos econômicos globais.

Bukharin apresentou o imperialismo enquanto fase do capitalismo na qual a concorrência interna (ao continente europeu) dos agentes produtivos não existia mais, e o capital monopólico expandira-se através do globo, principalmente através da forma financeira (BUKHARIN, 1976; PEREIRA, 2017). O capital tenderia a centralizar-se em grupos de elites específicas e, nesse processo, diferentes disputas inter-imperialistas ocorreriam. Essas seriam fruto da conformação global de estruturas na qual alguns países ocupariam o centro da economia e, através dessa posição, teriam primazia de exploração sobre as periferias majoritariamente agrícolas. 
A relação entre um centro econômico industrializado e uma periferia agrária também ocorre nas construções de Kautsky (1914). Para o autor, o imperialismo seria fruto de um descompasso de crescimento da indústria em relação ao meio agrícola. Enquanto a primeiro poderia continuamente expandir-se com readaptações tecnológicas, o segundo estaria condicionado pelos limitantes ecoambientais. O pioneiro capital europeu ampliaria sua região de domínio para ter acesso constante à matéria prima, superando as limitações do rural local e evitando o descompasso de fornecimento agroalimentar em relação à produção industrial. Assim como em Bukharin, conformar-se-ia uma estrutura econômica global de países centrais industriais com os demais enquanto subjacências agrárias (PEREIRA, 2017).

Já Rosa Luxemburgo trabalhou com a expansão não enquanto uma fase do capitalismo, mas enquanto ferramenta primordial do processo de acumulação (LUXEMBURGO, 1970; 1976). A autora argumentava que, na circulação de capital, seria essencial o elemento externo ao processo produtivo - que não o proletário e nem o capitalista - para que fosse possível a ampliação do capital, evitando a estagnação do mesmo em uma estrutura fechada. Em um primeiro momento esse elemento externo seriam profissionais liberais, militares, clero e afins; entretanto, esgotado esse contingente, a expansão global do capitalismo seria basal para viabilizar a acumulação e reprodução do sistema. Quando essa estrutura econômica não tivesse mais como disseminar-se, entraria em crise pela inviabilização da acumulação.

Em síntese, tem-se como fruto dos três autores um quadro no qual o capitalismo expandiu-se para além Europa na transição da Idade Contemporânea pela necessidade constante de matériaprima e pela busca por novos mercados que possibilitassem o ciclo de acumulação de capital, originado de (e originando) uma dinâmica de centralização e concentração dos fluxos, que seriam barrados somente em períodos de crise. Assim, o sistema econômico global seria conformado por regiões centrais e entornos periféricos agrícolas.

É em relação a esses pontos de síntese que as perspectivas de Braudel, Wallerstein, Arrighi e Fiori, sobre Sistema Mundo agregaram elementos importantes para o debate. Visto que esses autores trouxeram a ampliação da visão dos fluxos do capitalismo para uma esfera com diferentes níveis de análise, rompendo com a essencialidade econômica e somando dimensões culturais e políticas no debate acerca da disputa de posições na economia global (GRAZZIOTIN, 2019; COHEN, 1973).

Para Braudel (1987), pensar o processo global do capitalismo parte de três elementos centrais: (i) o mesmo ocupa um espaço geográfico específico, o qual pode alterar-se ao longo do tempo; (ii) essa amplitude tem um polo, que historicamente foram tanto Estados, como regiões, 
como cidades-Estado; e (iii) ao entorno desse centro, o sistema reparte-se em níveis de poder político econômico. Essa estrutura, originada pela conformação de dinâmicas sociais específicas, fundamentou mercados e Estados capitalistas, os quais, após emergirem no continente europeu, expandiram-se globalmente (WALLERSTEIN, 2004; FARIA, 1999).

$\mathrm{Na}$ leitura dos Sistemas $\mathrm{Mundo}^{2}$, quatro grandes momentos de circulação de capital seriam identificáveis, cada qual com seu polo, semiperiferias e periferias ${ }^{3}$. O primeiro ciclo centrou-se nas cidades-Estado de Gênova e Veneza, principalmente através do controle do comércio marítimo europeu e dos interesses financeiros no período entre os séculos XV e XVI. Já o ciclo seguinte foi marcado pelo crescimento holandês que dinamizou sua economia no momento da expansão marítima europeia e, com isso, centralizou a acumulação de capital no seu território no século XVII. O terceiro ciclo surgiu com a acumulação de capital em território britânico, promovida tanto pelo poderio marítimo do país, como pela industrialização e imperialismo realizado pelos mesmos ao longo do século XIX. Por fim, o século XX trouxe consigo o presente ciclo pautado na hegemonia norte americana e no padrão estadunidense de produção (FARIA, 1999; WALLERSTEIN, 1996). Cada ciclo de acumulação é marcado pela conversão internacional de moeda pautada por aquela referente ao país polo, salientando o poder financeiro dos mesmos (FIORI, 2015).

A centralidade dessas economias e seus efeitos institucionais sobre os demais países afetam as diferentes estâncias de produção e circulação de capital (WOOD, 2014; CHANG, 2004). Fluxos específicos são condicionados de acordo com o poder e ação dos países que ocupam uma posição de destaque no Sistema Mundo. É nesse espaço que podemos construir o debate sobre fluxos agroalimentares, e conceitualmente, Regimes Alimentares ${ }^{4}$.

A perspectiva dos Regimes Alimentares emergiu com Harriet Friedmann, na década de 80, quando a autora estudou os fluxos de trigo entre EUA e as demais economias (MCMICHAEL, 2009; FRIEDMANN, 1978). Progressivamente, e com a contribuição de outros autores, identificou-se como a produção agrícola global atendia a diretrizes específicas construídas e promovidas pelas nações que ocupassem o centro do processo de acumulação de capital. Ou seja, Estados com predomínio econômico e político conformariam mercados que os favorecem dentro

2 Braudel não utiliza o termo Sistema Mundo, mas Economia Mundo. Entretanto, diversas ponderações do próprio autor, de Wallerstein e outros já indicaram uma reciprocidade prática, apesar da terminologia distinta (GRAZZIOTIN, 2019)

3 É interessante notar como as leituras clássicas sobre imperialismo já caminhavam nessa direção de identificação, apesar de estarem muito mais enfocadas no período específico que vivenciavam.

4 É importante pontuar que McMichael (p. 28, 2016) entende os Regimes Alimentares enquanto uma interpretação própria e concorrente da pensada pelo Sistema Mundo. Entretanto, aqui busca-se a complementaridade das mesmas e como dialogam sobre elementos em comum e podem contribuir mutuamente. 
de especificidades que lhes sejam mais vantajosas. A partir desse disparador, chegou-se a leitura de três Regimes Alimentares (MCMICHAEL, 2016; SCHNEIDER, 2016).

O Primeiro Regime Alimentar centrou-se no Reino Unido entre 1870 e 1930 - sendo concomitante a ideia do Sistema Mundo de ciclo de acumulação inglesa. Com a expansão industrial, o Estado fomentou a formação de produções agrícolas que abastecessem a necessidade dupla de matéria-prima para as indústrias surgentes, bem como alimentos baratos a fim de reduzir o custo de manutenção da mão de obra - e aumentar a mais valia relativa. A ideia de divisão internacional do trabalho emergiu fortemente nesse momento, tendo na Inglaterra a construção do workshop of the world, enquanto os demais países foram pautados por uma caracterização agrícola (MCMICHAEL, 2016; FRIEDMANN, 1978).

Novamente, há para o Segundo Regime uma concomitância com os ciclos de acumulação do Sistema Mundo quando os EUA, no pós Segunda Guerra, emergiu como centro do Regime Alimentar. Nessa nova estrutura, que se manteve entre a década de 40 e a de 70, o meio rural foi condicionado por instituições que promoveram formas de modernização produtiva capitalista, bem como facilitação de pacotes tecnológicos estadunidenses (MCMICHAEL, 2016; FRIEDMANN, 1999). Ressalta-se que o período é caracterizado pela Guerra Fria e, portanto, as ações promovidas pelos Estados Unidos (e pelo bloco capitalista) bebiam profundamente numa disputa por hegemonia ideológica (MICHELENA, 1977). O anticomunismo e o desenvolvimentismo foram marcas salientes desse período e da interpretação geral para a produção agrícola (SCHNEIDER, 2016).

Entretanto, com as crises da década de 70 e com a ampliação sucessiva de poder de corporações transnacionais, o último quarto do século $\mathrm{XX}$ foi marcado pela emergência do Terceiro Regime Alimentar. O centro de poder sobre os fluxos agrícolas deslocou-se das mãos de um Estado específico para ser majoritariamente pautado pelos grandes conglomerados, dissipando sua concentração geográfica e mantendo a econômica (SCHNEIDER, 2016). O Regime Corporativo emergiu, então, como o projeto de globalização neoliberal no qual ampliou-se a porção e o poder de atuação do mercado capitalista sobre as demais estâncias, com destaque para dinâmicas de financeirização (MCMICHAEL, 2016). Diferentemente dos Regimes anteriores, ocorreu uma desconexão com os ciclos do Sistema Mundo, ainda que características primordiais da economia global continuassem centradas nos Estados Unidos - como a própria taxa de câmbio dolarizada.

É neste contemporâneo regime que diferentes questionamentos quanto aos hábitos alimentares emergem (LANG, 2005) - seja pela emergência da economia chinesa, pela 
conscientização de consumidores ou pela pauta ambiental -, bem como ao próprio sistema econômico em contínua crise (WOOD, 2014; ALMEIDA; PAULANI, 2011). E é nessa conjuntura incerta dos grandes ciclos contemporâneos que os dados a seguir serão analisados, buscando entender os locais centrais de produção alimentar e de significação desses alimentos no século XXI, bem como sua relação com a garantia nutricional das populações.

\section{Fluxos agroalimentares e estruturas globais}

Os dados expostos nessa sessão foram coletados das plataformas digitais da Organização para a Alimentação e Agricultura (FAO/ONU) e do Banco Mundial ${ }^{5}$. Selecionados de acordo com o potencial de obtenção das informações objetivadas. E, posteriormente, trabalhados em três blocos de análise.

No primeiro, analisou-se o Valor Agrícola Total produzido nos países e a percentagem de participação agrícola nos Produtos Internos Brutos. Os valores totais foram alcançados através da soma da produção nacional nos últimos vinte anos (2000 - 2018), utilizando o valor do dólar do triênio 2014-2016 como referenciação de moeda. O objetivo desse cálculo é evitar distorções decorrentes de possíveis safras instáveis ou condições específicas. Já os valores relativos ao PIB foram utilizados os de 2017 por ser o ano de maior número de observações disponíveis.

O segundo bloco, retoma a pergunta da introdução e a problematização específica sobre fatores alimentares ao trazer dados quantitativos relativos às condições nutricionais das diferentes nações. Para tal, trabalhou-se com observações sobre consumo proteico médio. Indicadores sobre insegurança alimentar e nutricional também serão abordados, entretanto de forma indireta quando da realização das correlações com outros dados - opção tomada frente a variabilidade da disponibilidade de dados.

Por fim, o terceiro bloco traz análises conjuntas sobre os elementos trabalhados anteriormente. Partiu-se da construção da correlação entre valores produtivos agroalimentares e nutricionais das populações - realizando uma projeção estatística através do LibreOffice Calc 7.0.3.1 - e, então, esboçou-se uma tipologia sobre perfis nacionais em relação a produção agrícola e garantia alimentar.

A quantidade total de países analisada em cada caso variou com a disponibilidade dos dados, entretanto buscou-se um quadro geral global, utilizando tantas informações quanto possível.

Quando analisa-se o total dos valores agrícolas dos países no século XXI, algumas informações específicas são proeminentes - como destacado na Tabela 1. Dentre os dez primeiros

5 Respectivamente $<$ fao.org/faostat/en/ $>$ e $<$ data.worldbank.org $>$ (acessados em 10/04/2021). 
em valor total - China, Estados Unidos, Índia, Brasil, Indonésia, Japão, Rússia, Turquia, Itália e Irã -, sete se localizam no continente asiático. Por mais que se possa tensionar as localizações parciais de Rússia e Turquia, e mesmo considerar o Oriente Médio à parte, ainda seriam parte predominante da amostragem principal.

Tabela 1 - Valor da produção agrícola total, 2000 - 2018.

\begin{tabular}{|c|c|c|c|c|c|c|c|}
\hline País & US\$ (milhões) & País & US\$ (milhões) & País & US\$ (milhões) & País & $\begin{array}{c}\text { US\$ } \\
\text { (milhões) }\end{array}$ \\
\hline China & $\$ 19.561 .629,96$ & Peru & $\$ 227.165,83$ & Laos & $\$ 72.839,57$ & Eslovênia & $\$ 17.899,96$ \\
\hline EUA & $\$ 6.289 .871,51$ & Marrocos & $\$ 211.420,30$ & Ruanda & $\$ 70.660,87$ & Porto Rico & $\$ 14.727,35$ \\
\hline Índia & $\$ 5.666 .018,47$ & Quênia & $\$ 206.973,35$ & Chade & $\$ 70.024,06$ & R.C. Africana & $\$ 12.918,19$ \\
\hline Brasil & $\$ 2.982 .770,12$ & Aráb. Saudita & $\$ 201.129,47$ & Noruega & $\$ 69.061,14$ & Fiji & $\$ 7.995,20$ \\
\hline Indonésia & $\$ 2.044 .115,17$ & Cazaquistão & $\$ 180.883,39$ & Zimbábue & $\$ 67.678,59$ & Butão & $\$ 7.265,00$ \\
\hline Japão & $\$ 1.695 .909,84$ & Bélgica & $\$ 157.808,71$ & Sérvia & $\$ 66.451,69$ & Timor-Leste & $\$ 6.906,51$ \\
\hline Rússia & $\$ 1.312 .526,85$ & Suíça & $\$ 149.674,87$ & Benin & $\$ 61.739,92$ & Trinidade e Tobago & $\$ 6.820,07$ \\
\hline Turquia & $\$ 1.192 .993,55$ & Equador & $\$ 147.752,13$ & Turcomenistão & $\$ 58.383,09$ & Namíbia & $\$ 5.371,73$ \\
\hline Itália & $\$ 989.888,37$ & C. do Marfim & $\$ 145.837,33$ & Honduras & $\$ 51.200,87$ & Belize & $\$ 4.912,42$ \\
\hline Irã & $\$ 902.365,60$ & Belarus & $\$ 144.831,30$ & Congo & $\$ 51.010,38$ & Luxemburgo & $\$ 4.837,69$ \\
\hline Alemanha & $\$ 894.898,64$ & Gana & $\$ 140.892,82$ & Quirguistão & $\$ 50.328,97$ & Cabo Verde & $\$ 4.373,96$ \\
\hline Paquistão & $\$ 869.460,57$ & Camarões & $\$ 135.791,49$ & Zâmbia & $\$ 49.275,06$ & Islândia & $\$ 4.345,43$ \\
\hline México & $\$ 826.310,87$ & Hungria & $\$ 132.843,52$ & Líbano & $\$ 47.841,33$ & Kuwait & $\$ 4.073,00$ \\
\hline Nigéria & $\$ 814.062,21$ & Nepal & $\$ 131.663,02$ & Burkina Faso & $\$ 46.515,34$ & Suriname & $\$ 3.860,71$ \\
\hline Espanha & $\$ 804.406,85$ & Portugal & $\$ 131.014,61$ & Serra Leoa & $\$ 42.707,64$ & Palestina & $\$ 3.857,14$ \\
\hline Argentina & $\$ 803.572,03$ & Irlanda & $\$ 130.608,89$ & Panamá & $\$ 41.843,28$ & Gâmbia & $\$ 3.765,40$ \\
\hline Coreia do Sul & $\$ 745.935,35$ & Malawi & $\$ 129.119,60$ & Jordânia & $\$ 40.036,22$ & Guiana & $\$ 3.255,05$ \\
\hline Canadá & $\$ 742.548,28$ & Israel & $\$ 128.949,25$ & Jamaica & $\$ 39.245,75$ & Malta & $\$ 2.904,01$ \\
\hline Vietnã & $\$ 687.204,34$ & Tanzânia & $\$ 120.985,60$ & Mauritânia & $\$ 38.504,80$ & Vanuatu & $\$ 2.591,84$ \\
\hline Tailândia & $\$ 676.938,00$ & Áustria & $\$ 120.295,08$ & Lituânia & $\$ 38.351,87$ & Barbados & $\$ 2.575,10$ \\
\hline Austrália & $\$ 661.007,46$ & Mali & $\$ 119.765,64$ & Eslováquia & $\$ 37.788,70$ & Brunei & $\$ 2.507,49$ \\
\hline Venezuela & $\$ 655.253,37$ & Cambodja & $\$ 118.591,39$ & Albânia & $\$ 36.564,42$ & Guiné Equatorial & $\$ 2.423,93$ \\
\hline Filipinas & $\$ 570.513,12$ & Paraguai & $\$ 114.052,85$ & El Salvador & $\$ 35.738,60$ & Omã & $\$ 2.393,42$ \\
\hline Reino Unido & $\$ 540.284,20$ & Bolívia & $\$ 109.336,40$ & Togo & $\$ 35.413,23$ & Samoa & $\$ 2.178,16$ \\
\hline Egito & $\$ 520.907,34$ & Iêmen & $\$ 101.230,83$ & Nicarágua & $\$ 34.404,47$ & Qatar & $\$ 2.002,80$ \\
\hline Ucrânia & $\$ 440.434,31$ & $\begin{array}{l}\text { República } \\
\text { Dominicana }\end{array}$ & $\$ 92.340,17$ & Tadjiquistão & $\$ 31.308,63$ & $\begin{array}{l}\text { São Vicente e } \\
\text { Granadinas }\end{array}$ & $\$ 1.672,09$ \\
\hline Polônia & $\$ 403.780,90$ & Iraque & $\$ 90.438,22$ & Burundi & $\$ 29.964,93$ & Nova Caledônia & $\$ 1.635,71$ \\
\hline Malásia & $\$ 372.033,40$ & Costa Rica & $\$ 88.325,47$ & Eritreia & $\$ 26.756,08$ & Grenada & $\$ 1.384,62$ \\
\hline Colômbia & $\$ 360.995,99$ & Uruguai & $\$ 87.054,58$ & $\begin{array}{c}\text { Bósnia e } \\
\text { Herzegóvina }\end{array}$ & $\$ 25.718,93$ & Santa Lucia & $\$ 1.339,60$ \\
\hline Bangladesh & $\$ 344.406,10$ & Niger & $\$ 86.674,85$ & Armênia & $\$ 25.379,81$ & Singapura & $\$ 1.283,14$ \\
\hline Argélia & $\$ 332.761,37$ & Tunísia & $\$ 80.791,34$ & Moldova & $\$ 24.684,77$ & Botsuana & $\$ 1.208,43$ \\
\hline África do Sul & $\$ 324.104,39$ & Sri Lanka & $\$ 79.814,50$ & Guiné & $\$ 23.899,88$ & Antígua e Barbuda & $\$ 621,64$ \\
\hline Grécia & $\$ 315.728,14$ & Suécia & $\$ 78.944,63$ & Guiné-Bissau & $\$ 22.665,12$ & Ilhas Cook & $\$ 400,67$ \\
\hline Romênia & $\$ 310.396,39$ & Moçambique & $\$ 78.340,33$ & Geórgia & $\$ 21.754,44$ & Seychelles & $\$ 352,47$ \\
\hline Holanda & $\$ 288.558,17$ & Angola & $\$ 76.680,10$ & Senegal & $\$ 20.283,58$ & Maldivas & $\$ 324,88$ \\
\hline
\end{tabular}




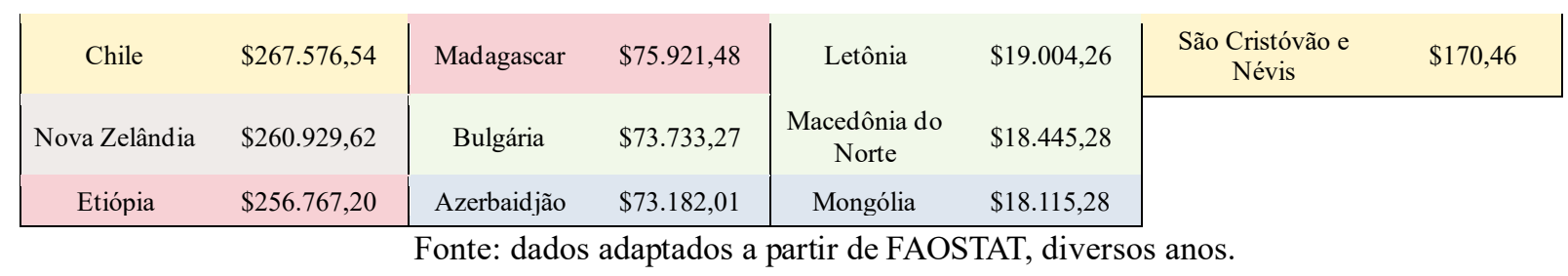

É notável a não reciprocidade entre extensão territorial e valor produzido pela agricultura, visto que países de tamanho reduzido - como Itália, Alemanha, Japão, Coreia do Sul e Vietnã apresentam produções totais maiores do que outros de extensão elevada - como Austrália, Arábia Saudita e Cazaquistão. Entretanto, o inverso é constatado quando países de menores produções são, em sua maioria, também aqueles de dimensão diminuta.

A desproporção identificada em alguns casos entre valor total e disponibilidade de território remete ao debate sobre valor agregado na produção agrícola e amplitude das cadeias de valores (POZO-VERGNES; VORLEY, 2015; GEREFFI et al, 2005). O estudo de Schwarz et al (2016) sobre aspargos comercializados na Bélgica é bastante ilustrativo dessa relação. No mesmo, as autoras e autores apontam para diferentes relações de valor dependendo da origem produtiva do vegetal - no próprio território belga, ou importado do Peru. Essa desproporção, inclusive, acarreta em diferentes valores recebidos pelos próprios produtores de acordo com as estruturas de mercado e comercialização nas quais se inserem.

Em relação aos países de menor valor total, há uma forte conexão com a dependência de exportação de outros elementos. Por exemplo, os casos de Namíbia e Botsuana que tem na extração de diamantes parte essencial de suas balanças externas ${ }^{6}$. O mesmo ocorre com a dependência de exportação de petróleo nas economias de Kuwait e Trinidad e Tobago. Essas dinâmicas endossam peculiaridades dos Regimes Alimentares nos quais os países especializam-se em produções específicas na dinâmica internacional, tornando-se dependentes do mercado capitalista global para acesso a outros produtos - como a própria produção agroalimentar. Desenhando um desfavorecimento da segurança alimentar em benefício de exportações (MCMICHAEL, 2016).

Para contextualizar os Valores Agrícolas Totais, a proporcionalidade da produção agrícola no Produto Interno Bruto fornece acréscimos interessantes. De forma abrangente, três grupos de países - de acordo com as proporcionalidades - podem ser interpretados, conforme apresentado na Figura 1.

6 Porcentagens de 21,04\% para Namíbia, e 74,3\% para Botsuana. Conforme dados de Harvard Atlas, disponíveis em: < atlas.cid.harvard.edu/countries/> (acesso em 12/04/21). 
Figura 1 - Percentagem do valor total agrícola no PIB total dos países (2017).
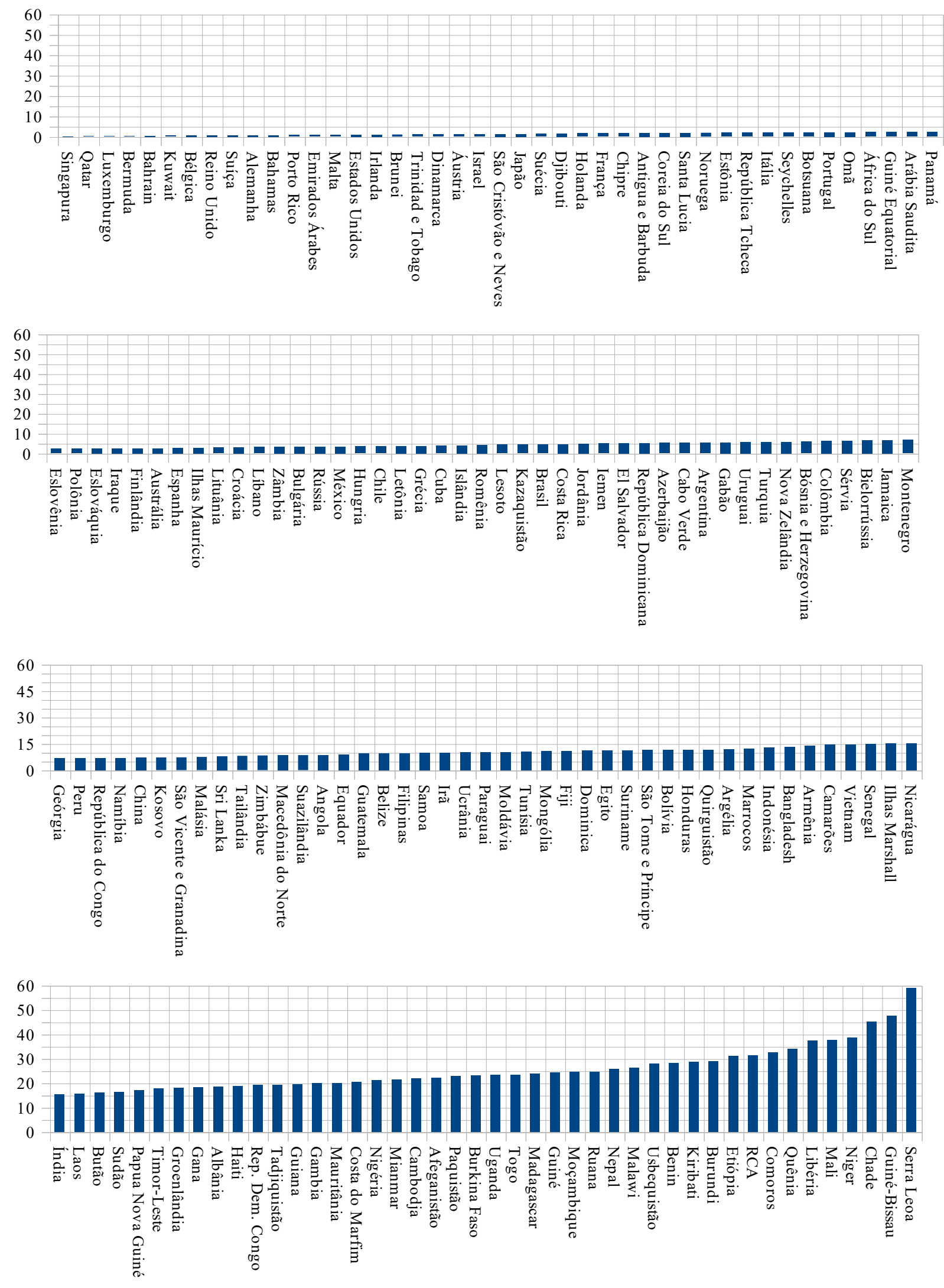

Fonte: FAOSTAT, 2017 - 2019. 
Em uma primeira faixa, estão aqueles com até cinco por cento de importância da agricultura na composição do seu Produto Interno Bruto. Nesse grupo apresentam-se países que compõe o quadro político da Organização para Cooperação e Desenvolvimento Econômico (OCDE), os quais - em teoria - obtém parâmetros de desenvolvimento econômico capitalista dentro do ideal promovido pela Organização Mundial de Comércio (BRESSER PEREIRA, 2014). A posição desses países endossa teorias que apontam para uma retração no setor primário em países desenvolvidos para o capitalismo, com ampliação das produções industriais e, principalmente, do setor terciário (FEIJÓ; OREIRO, 2010). Outras realidades que se apresentam nessa faixa são aquelas com uma profunda dependência de outras mercadorias, sejam os casos de Botsuana e Kuwait, supracitados, ou aqueles de forte interlocução financeira no mercado global, como o caso de Luxemburgo.

É essencial salientar que diversos países com baixa participação da agricultura em seus produtos internos apresentam valores bastante elevados de produção agrícola total. Novamente, possibilitando o vislumbre de produções de maior valor agregado dentro de países específicos da composição econômica internacional (GEREFFI et al, 2005).

$\mathrm{Na}$ faixa seguinte, países próximos ao intervalo entre cinco e quinze por cento de participação agrícola nos seus produtos internos. Retomando as proposições sobre os Sistema Mundo, Wallerstein (1994) aponta como a semi periferia intercala posições produtivas entre práticas do centro da economia capitalista, e práticas da periferia. Hora essas nações apareceriam como impulsoras no processo de produção, hora como suplementares. Essa caracterização enquadra-se com adequação ao analisarmos que países na faixa percentual específica são, frequentemente, economias entendidas enquanto em ascensão nas últimas décadas, como o caso de China, Indonésia, Índia e Vietnã. É nesta que encontram-se, também, países da América Latina, Leste Europeu, Oriente Médio e Magrebe Africano.

Por fim, na terceira faixa, países acima de quinze por centro de participação agrícola no PIB, chegando a um máximo de cinquenta e oito por cento, no caso de Serra Leoa. Nessa seleção estão estruturas nacionais que passaram por intensos processos de imperialismo sobre suas estruturas e que ainda apresentam desgastes internos em decorrência das sequelas deixadas pelo período de domínio europeu (WOOD, 2014, VISENTINI et al, 2012). Destacam-se, nessas situações, casos como os de Quênia, Mali, Libéria e Myanmar marcados por guerras civis e outros conflitos internos. A predominância da produção agrícola na estrutura econômica ilustra os argumentos apontados nos debates clássicos sobre imperialismo e expansão do capitalismo, nos quais 
apontava-se para a conformação de uma periferia profundamente agrícola frente a um centro majoritariamente industrial ${ }^{7}$ (GRAZZIOTIN, 2019).

Por sua vez, quando analisa-se os dados relativos ao consumo proteico diário, as informações são semelhantes, ainda que em proporção inversa. É interessante o apontamento de que essa observação engloba diferentes níveis da alimentação, não ficando restrito à proteína animal. São contabilizadas também as proteínas decorrentes de grãos, hortaliças e, propriamente, carnes.

Entretanto, é no específico da carnificação das dietas que moram relações bastante assíduas de ocidentalização das práticas alimentares. Como aponta McMichael (2016), diferentes casos evidenciam uma correlação entre ampliação da conexão do país com a economia internacional e incremento de consumo de proteína animal. Por exemplo, as alterações alimentares ocorridas no Japão na segunda metade do século XX que ocasionou um progressivo aumento da aquisição de carne no país.

Considerando que a média global de consumo diário de proteínas é de 90,2 gramas (SCHNEIDER. 2014), três subdivisões foram trabalhadas de acordo com a ingestão dos diferentes países, conforme perceptível pela Figura 2.

Um primeiro grupo de países apresenta índices de consumo bastante abaixo da média global. São aqueles que os valores apontam para consumos entre 38,40 gramas, como no caso da Libéria, a situações como de Gana, Suriname e Índia, que se aproximam de 60 gramas diárias por pessoa. Neste montante, é notável o caso de realidades com conflitos internos ou processos de exclusão e rompimentos históricos - ilustrado pelos casos liberianos, haitianos e indianos. Outro elemento interessante é a inexistência de reciprocidade entre o consumo específico e a tendência das economias na última década - vide o caso nigeriano que, apesar de apresentar taxas de crescimento constante na década de 2010, ainda apresenta valores bastante baixos no quesito nutricional ${ }^{8}$.

7 É essencial salientar que, por trabalhar desde uma perspectiva macro, o artigo constrói generalizações que não pretendem traduzir as realidades nacionais em sua completude, mas sim, esboçar, dentro das limitações, quadros gerais das trajetórias econômicas e sociais analisadas. Assim sendo, as taxações não pretendem-se deterministas, mas ilustrações das condições historicamente apresentadas para as distintas realidades nacionais.

8 Por anos o crescimento do Produto Interno Bruto nigeriano, no século XXI, aproximou-se de seis por cento. Porém, por ser profundamente dependente de exportações petrolíferas, apresentou forte queda nos últimos anos. Dados de $<$ bit.ly/3dWeXza $>$ (acesso em 14/04/2021) e < ufrgs.br/cebrafrica/2019/09/03/crescimento-economicoda-nigeria-desacelera-diante-da-queda-do-preco-do-petroleo/> (acesso em 12/04/2021). 
Figura 2 - Ingestão média de proteínas (gramas/pessoa/dia), média trianual 2016/17/18.
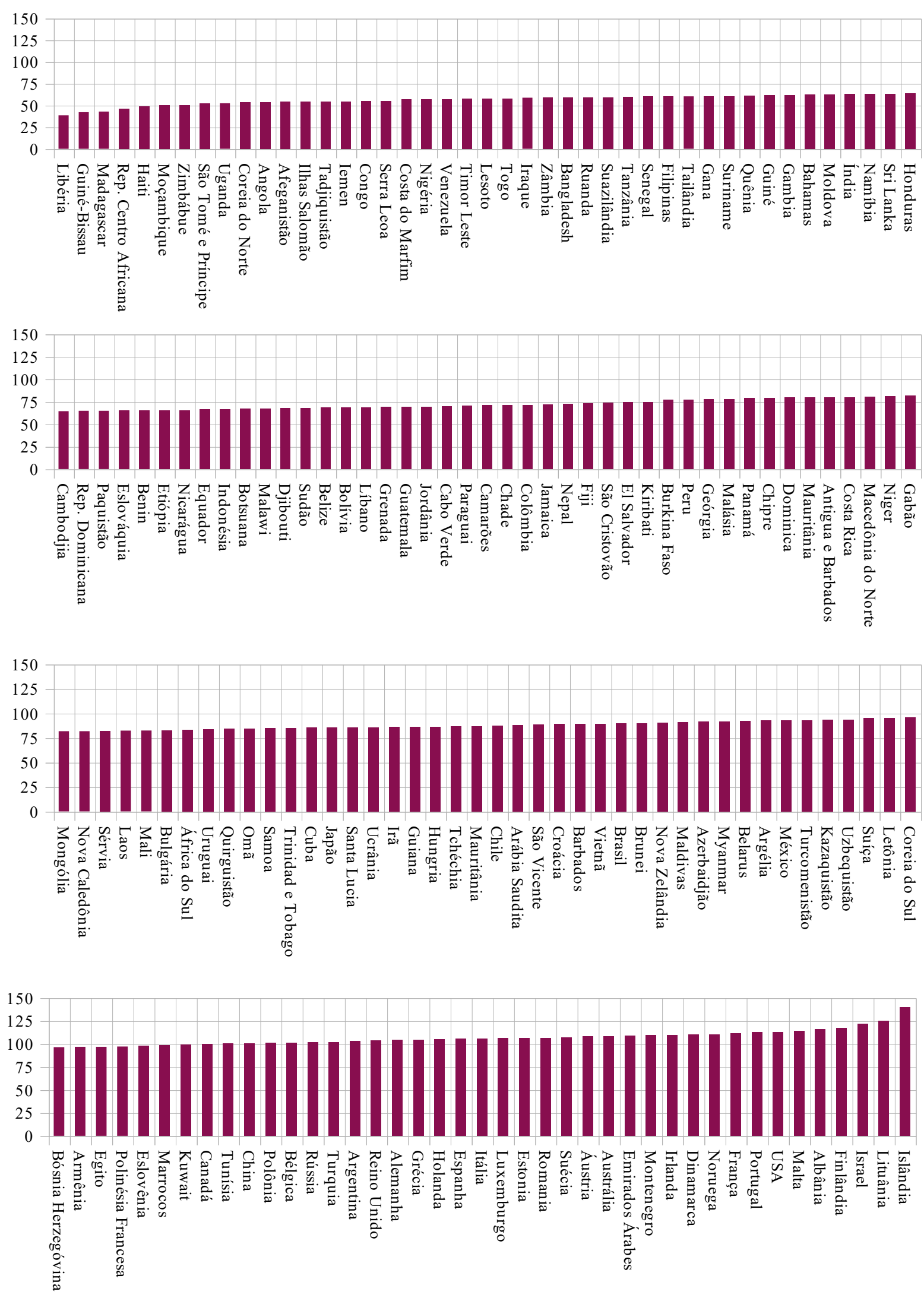

Fonte: FAOSTAT, 2018. 
O segundo grupo aloca-se no o limite do primeiro e um pouco acima da média global - entre 60 e aproximadamente 100 gramas de proteína diárias por pessoa. Nesse ainda apresentam-se países com um histórico de desigualdades sociais, porém, que nas últimas décadas, tem promovido tentativas de superação dessas cicatrizes. Da perspectiva do Sistema Mundo, são países que por vezes flertam com posições de semi periferias, ou ao menos periferias mais distantes das margens (FIORI, 2015). Apresentam-se aqui casos como África do Sul, Colômbia, Hungria, Chile, México, Coreia do Sul, Brasil e China.

Salienta-se que os consumos apresentados referem-se à média geral do país, desconsiderando as discrepâncias internas na quantificação dos dados. O caso chinês é bastante emblemático visto que, apesar da alta média geral, dentro do país apresentam-se distinções. Em $2012,35,71 \mathrm{~kg}$ de proteína animal nas cidades frente um valor de 29,32 $\mathrm{kg}$ para o meio rural, por exemplo (SCHNEIDER, 2014; HUANG, 2011).

Por fim, o terceiro grupo apresenta médias gerais acima de 100 gramas. Nessa seleção, estão majoritariamente países do norte global - notadamente oeste europeu e Estados Unidos. Além disso, a maior parte desses não indica participação elevada da produção agrícola nos seus produtos internos totais. Inserem-se nesse grupo exatamente aqueles países que, historicamente, habitaram as posições centrais das disputas internacionais e, por diversas vezes, exerceram poder e exploração sobre os anteriormente apresentados.

Para visualização sobre a conexão entre os dados, a Tabela 2 traz a correlação estabelecida entre valor agrícola; percentagem da agricultura no PIB; consumo médio de proteínas diárias; taxa de subnutrição; obesidade; exportação agrícola total; importação agrícola total; e percentagem da população em insegurança alimentar severa ou moderada. A amostragem foi de 179 países, sendo considerados todos que apresentassem ao menos duas variáveis das oito trabalhadas.

Os dados evidenciam a correlação entre consumo proteico e insegurança alimentar enquanto inversamente proporcional. Afirmando a situação na qual países com menor consumo de proteínas em geral tendem a ter um nível maior de insegurança alimentar. Assim, os grupos utilizados para debate sobre consumo proteico também serviriam de aproximação com situações de insegurança alimentar severa ou moderada. Da mesma forma, a tendência visualizada ocorre em relação às taxas de subnutrição.

Ainda no consumo diário de proteínas, apresenta-se proporção positiva à percentagem da população em situação de obesidade. Elemento que tensiona a qualidade e o modo da alimentação das populações, tanto da problemática das condições nutricionais as quais se tem acesso, como da significação de consumo alimentar em suas diferentes dimensões (SCHNEIDER, 2014). Como 
aponta Friedmann (1999), a mercantilização agroalimentar no final do século XX levou ao abandono de alimentações diversificadas e localizadas para a homogeneização das tradições de alimentação a partir de um ideal de consumo específico, profundamente pautado em alimentos de maior processamento e de produção massificável.

Tabela 2 - Correlação entre diferentes elementos.

\begin{tabular}{|c|c|c|c|c|c|c|c|c|}
\hline & $\begin{array}{c}\text { Consumo } \\
\text { médio de } \\
\text { proteina }\end{array}$ & $\begin{array}{c}\text { Insegurança } \\
\text { alimentar } \\
\text { severa ou } \\
\text { moderada }\end{array}$ & $\begin{array}{l}\text { Valor agrícola } \\
\text { total }\end{array}$ & $\begin{array}{c}\text { Participação } \\
\text { Agrícola no } \\
\text { PIB }\end{array}$ & Subnutrição & Obesidade & $\begin{array}{l}\text { Exportação } \\
\text { agricola total }\end{array}$ & \begin{tabular}{|} 
Importação \\
agricola total
\end{tabular} \\
\hline $\begin{array}{l}\text { Consumo médio de } \\
\text { proteina }\end{array}$ & $100,00 \%$ & & & & & & & \\
\hline $\begin{array}{l}\text { Insegurança alimentar } \\
\text { severa ou moderada }\end{array}$ & $-78,13 \%$ & $100,00 \%$ & & & & & & \\
\hline Valor agrícola total & $12,71 \%$ & $-16,95 \%$ & $100,00 \%$ & & & & & \\
\hline $\begin{array}{c}\text { Participação Agrícola } \\
\text { no PIB }\end{array}$ & $-53,39 \%$ & $72,60 \%$ & $-5,80 \%$ & $100,00 \%$ & & & & \\
\hline Subnutrição & $-71,60 \%$ & $84,29 \%$ & $-9,32 \%$ & $59,96 \%$ & $100,00 \%$ & & & \\
\hline Obesidade & $46,72 \%$ & $-47,09 \%$ & $-8,70 \%$ & $-52,83 \%$ & $-48,81 \%$ & $100,00 \%$ & & \\
\hline $\begin{array}{l}\text { Exportação agrícola } \\
\text { total }\end{array}$ & $35,95 \%$ & $-31,91 \%$ & $47,73 \%$ & $-24,89 \%$ & $-25,00 \%$ & $15,42 \%$ & $100,00 \%$ & \\
\hline $\begin{array}{c}\text { Importação agrícola } \\
\text { total }\end{array}$ & $36,29 \%$ & $-36,68 \%$ & $67,86 \%$ & $-26,47 \%$ & $-24,62 \%$ & $8,47 \%$ & $81,81 \%$ & $100,00 \%$ \\
\hline
\end{tabular}

Fonte: Participação agrícola no PIB total - 2018 (FAO); Soma Exportações e Importações - 2000-2018 (Banco

Mundial); Soma Valor Agrícola total - 2000-2018 (FAO); Consumo médio de proteína - média trienal 2015/2017 (FAO); Insegurança Alimentar severa ou moderada - média trianual 2014/2016 (FAO); Subnutrição - média trianual 2014/2016 (FAO); Obesidade entre a população adulta - média trianual 2015/2017 (FAO).

Por sua vez, o valor agrícola total dispõe de baixa simetria em relação ao consumo proteico. Indicando que, não necessariamente, países com uma alta produção agrícola em valor apresentam um consumo interno equitativo. Ponto perceptível quando analisamos o exemplo do caso nigeriano que aparece como um dos maiores produtores em valor - US\$ 814.062,21 milhões -, simultâneo a uma baixa ingestão diária média - 57,0 gramas diárias por pessoa. Distribuições como essa endossam os Regimes Alimentares, nos quais países podem se tornar grandes produtores agrícolas sem, entretanto, produzirem de forma suficientemente alocada para manutenção da sua população interna (MCMICHAEL, 2016).

Nota-se, também, que as taxas de importação e exportação agrícola apresentam uma forte covariação, indicando perfis de economias que mercantilizam profundamente suas práticas agroalimentares (PLEIN, 2010; BERSTEIN, 1977). Fator que ganha uma nova camada quando 
constatada correlação entre participação da agricultura no PIB enquanto proporcional à insegurança alimentar. Ou seja, dilema de países com estruturas econômicas majoritariamente agrícolas tendendo a um menor acesso da população a alimentos.

Para explorar esse elemento da relação entre economia mercantilizada e garantias alimentares, a Figura 3 traz a relação entre consumo de proteínas, participação da agricultura no PIB nacional e o Valor Agrícola Total para diferentes países. Através da construção de uma média central às três variáveis, traçou-se uma tipologia pautada em classificação por classes (MARRADI, 1990) para esboçar perfis gerais de realidades nacionais.

Figura 3 - Gráfico de consumo de proteínas; participação da agricultura no PIB e Valor Agrícola Total.

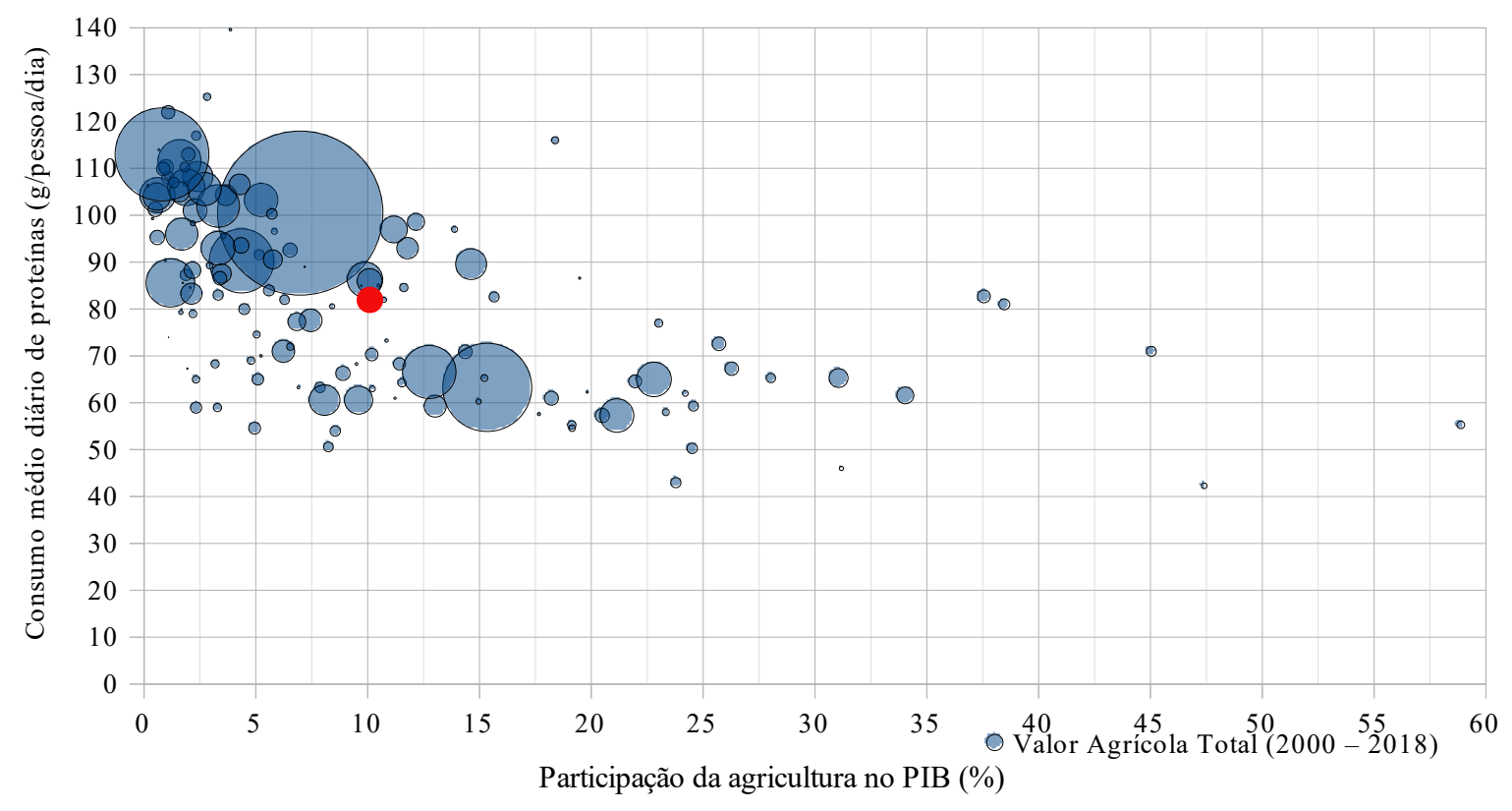

Fonte: FAOSTAT e Banco Mundial (vários anos)

Os critérios utilizados foram os de situações acima ou abaixo da participação média da agricultura no PIB e idem para o consumo médio de proteínas, formando quatro categorias finais apresentadas na Tabela 3 . 
Tabela 3 - Tipologia das condições agroalimentares nacionais.

\begin{tabular}{|c|c|c|}
\hline & $\begin{array}{l}\text { (a) } \\
\text { Consumo diário de proteínas abaixo da média global }\end{array}$ & $\begin{array}{l}\text { (b) } \\
\text { Consumo diário de proteínas acima da média global }\end{array}$ \\
\hline $\begin{array}{l}\text { (A) } \\
\text { Participação } \\
\text { da agricultura } \\
\text { no PIB } \\
\text { abaixo da } \\
\text { média global }\end{array}$ & $\begin{array}{l}\text { (Aa) } \\
\text { Angola; Antígua e Barbados; Belize; Botsuana; Cabo Verde; } \\
\text { Chipre; Costa Rica; Colômbia; El Salvador; Equador; } \\
\text { Eslováquia; Filipinas; Iêmen; Iraque; Jamaica; Jordânia; } \\
\text { Líbano; Macedônia do Norte; Malásia; Namíbia; Panamá; } \\
\text { Peru; República Dominicana; Sri Lanka; São Cristóvão; } \\
\text { Tailândia; Zâmbia; Zimbábue. }\end{array}$ & $\begin{array}{l}\text { (Ab) } \\
\text { África do Sul; Alemanha; Austrália; Áustria; Arábia Saudita; } \\
\text { Argentina; Azerbaidjão; Belarus; Bélgica; Brasil; Bulgária; } \\
\text { Brunei; Bósnia Herzegóvina; Cazaquistão; China; Chile; } \\
\text { Coreia do Sul; Croácia; Dinamarca; Espanha; Eslovênia; } \\
\text { Estônia; EUA; Finlândia; França; Groenlândia; Grécia; } \\
\text { Holanda; Hungria; Itália; Israel; Irlanda; Japão; Kuwait; } \\
\text { Letônia; Lituânia; Luxemburgo; Malta; México; Noruega; } \\
\text { Nova Zelândia; Omã; Polônia; Portugal; República Tcheca; } \\
\text { Reino Unido; Romênia; Rússia; São Vicente; Santa Lusia; } \\
\text { Sérvia; Suécia; Suíça; Tunísia; Uruguai. }\end{array}$ \\
\hline $\begin{array}{l}\text { (B) } \\
\text { Participação } \\
\text { da agricultura } \\
\text { no PIB acima } \\
\text { da média } \\
\text { global }\end{array}$ & $\begin{array}{l}\text { (Ba) } \\
\text { Bangladesh; Benin; Bolívia; Burkina Faso; Cambodja; } \\
\text { Camarões; Chade; Costa do Marfim; Congo; Etiópia; Fiji; } \\
\text { Gâmbia; Gana; Guiné; Guiné-Bissau; Honduras; Indonésia; } \\
\text { Índia; Mali; Malauí; Madagascar; Moçambique; Moldávia; } \\
\text { Nepal; Nicarágua; Níger; Nigéria; Paquistão; Paraguai; } \\
\text { Quênia; República Centro Africana; Ruanda; Serra Leoa; } \\
\text { Senegal; Suriname; Tadjiquistão; Timor-Leste; Togo. }\end{array}$ & $\begin{array}{l}\text { (Bb) } \\
\text { Albânia; Argélia; Armênia; Egito; Guiana; Irã; Laos; } \\
\text { Marrocos; Mongólia; Quirguistão; Samoa; Trinidade e } \\
\text { Tobago; Ucrânia; Vietnã. }\end{array}$ \\
\hline
\end{tabular}

Fonte: elaboração própria a partir dos dados de FAOSTAT e Banco Mundial.

Ficam evidentes, através da tipologia, os quadros explorados separadamente nos critérios anteriores. Contata-se que os países agrupam-se massivamente em dois grandes blocos ( $A b$ e $B a)$, sendo reduzidos nas outras classificações $(A a \text { e } B b)^{9}$.

Na composição $A b$, apresenta-se consumo de proteínas acima da média, conjuntamente com uma participação da agricultura no PIB abaixo da média global. Essa designação pode indicar uma gestão eficiente das possibilidades agroalimentares do país, bem como uma forte inserção no mercado internacional - vide a correlação entre consumo médio de proteínas e importação apresentada na Tabela 2. Com essa leitura não aponta-se para uma defesa do modo de inserção global utilizado pela maior parte dos países nesse grupo, mas que, dentro da estrutura econômica internacional e através de mercados capitalistas, essas nações utilizaram ferramentas eficientes do ponto de vista da manutenção da sua estrutura alimentar. Não se desconsidera a trajetória histórica, tampouco as implicações socioambientais ou nutricionais dos modelos desenvolvidos, mas salienta-se a prática dentro da estrutura vigente. Nota-se aqui a alta concentração de países com elevado valor agrícola total no século XXI e diversas estruturas nacionais que apresentaram processos de crescimento econômico em algum período da temporalidade utilizada - casos de África do Sul, Brasil, China e Índia, por exemplo.

Já na composição $B a$, encontram-se aqueles com uma alta participação agrícola no Produto Interno Bruto, porém que não apresentam valores acima da média global para consumo de

9 É essencial o destaque de que a tipologia enquanto pautada apenas em critérios numéricos abre espaço para generalizações. Por exemplo, a diferença de gramas diárias de consumo de proteína entre Guiana $(B b)$ e República Tcheca $(A b)$ é de 86 para 87 gramas. Assim, um aprofundamento específico seria necessário para discernir os diferentes casos. Entretanto, tais práticas tornam-se inviáveis no espaço-tempo disponível. 
proteínas de sua população. Como relacionado anteriormente, encontram-se com piores indicadores países que, historicamente, tiveram seus territórios invadidos e explorados por nações estrangeiras, fragmentando a formação de estruturas nacionais (VISENTINI et al, 2012). A realidade indiana é ilustrativa desse processo visto que, apesar do crescimento econômico nas últimas décadas, ainda apresenta fortes desigualdades, evidenciando cicatrizes do processo formativo nacional marcado pelo período colonial inglês.

Já os grupos $B b$ e $A a$ conjugam situações abaixo ou acima da média para ambos os elementos. É menor a quantidade relativa de países em ambas as categorias. No caso dos que apresentam consumo e participação agrícola maior do que o padrão global, em sua maior parte aproximam-se aos valores do grupo $A b$. Os quadros nacionais apresentados são de distintas trajetórias históricas e de realidades presentes também dispares, inviabilizando uma leitura generalizada. Já na $A a$, os países apresentam valores bastante baixos de produção agrícola total no século XXI, além de valores de consumo proteico diário aquém da média. Fatores como dependência de turismo, participação econômica do narcotráfico, escolhas políticas e fortes desigualdades regionais históricas podem ser elementos explicativos para tal quadro, entretanto ambas as categorias exigiriam aprofundamentos individualizados.

A composição de diferentes quadros econômicos e agroalimentares dialoga com Wallerstein sobre os papéis e possibilidades de centro, semiperiferia e periferias do Sistema Mundo. Todos os níveis disporiam de importância agrícola e não agrícola em suas composições econômicas, porém a predominância dos setores seria alterada de acordo com a posição internacional das realidades nacionais (WALLERSTEIN, 2004; 1992; FARIA, 1999). Países centrais disporiam de elevada diversificação econômica interna, alto valor agregado em sua produção - seja agrícola ou não agrícola -, e hábitos de consumo específicos. Enquanto países periféricos estariam envoltos em práticas econômicas de menor valor à nível do comércio internacional, baseando suas dinâmicas produtivas em economias de escala como forma de manterem o lucro das elites internas (GRAZZIOTIN, 2019; OLIVEIRA, 2018).

Para a visão do Sistema Mundo, bem como para os Regimes Alimentares, não haveria espaço internacional para rompimentos dentro do mercado capitalista com a lógica econômica que se impõe sobre esses países. Assim, os mesmos não desempenhariam práticas majoritariamente agrícolas enquanto uma etapa de um processo desenvolvimentista, mas pela conformação das estruturas internacionais que limitariam possibilidades de transformação socioeconômica em países periféricos (FIORI, 2015). Apesar das ações e motivações das estruturas nacionais, as 
instituições e estruturas internacionais condicionariam os caminhos trilháveis dentro da lógica de mercados capitalistas globais (CHANG, 2004).

É partindo da leitura internacionalista e dos dados apresentados, que a seção seguinte reflete sobre a pergunta da introdução sobre o percurso dos alimentos na contemporaneidade.

\section{A quantidade e a qualidade dos elos}

Em artigo de 1999, Harriet Friedmann aponta para as diferentes tradições alimentares que compõe práticas humanas. Ao longo do século XX e, em especial da segunda metade do mesmo, diferentes hábitos nutricionais foram substituídos por consumos específicos. Costumes alimentares das distintas localidades foram convertidos em tradições "modernas" promovidas, principalmente, pela Revolução Verde e pelos Food Aid estadunidenses.

Soma-se a essa "nova tradição alimentar", a ascensão de diretrizes da Organização Mundial do Comércio, na década de 90, estruturando um arquétipo de alimentação perpassado por bases mercadológicas capitalistas - seja na obtenção de recursos, ou na comercialização final da colheita (PLEIN, 2010). Assim, produz-se para comercializar e, com a renda obtida, adquirir alimentos. Como exemplifica Friedmann (1999), diversos agricultores no México nunca teriam acesso ao alimento que produzissem, visto que esse seria comercializado por um valor muito maior com exportadores do que o valor proporcional ao consumo direto.

$\mathrm{Na}$ mercantilização capitalista dos processos agroalimentares, países ocupam posições produtivas específicas na economia mundo, tornando-se majoritariamente exportadores sem que isso, necessariamente, converta-se em segurança alimentar para a população local (WALLERSTEIN, 1992), conforme ilustrado na seção anterior. Os fluxos entre as diferentes nações - ou mesmo internamente a essas - ocorre através do estímulo de aptidões geográficas e históricas a fim de gerar polos produtivos especializados que possam abastecer mercados internacionais em potencial. Para manter a eficácia produtiva capitalista, essas cadeias impõem a padronização das matérias-primas, forçando a commoditização dos produtos - no caso, os agroalimentares (MARINHO, 2013; GEREFFI; LEE, 2012).

Convenciona-se, então, um quadro com três eixos centrais: (i) produtos padronizados, (ii) comercializados através de longas cadeias de mercado e (iii) operacionalizados sobre um comércio global profundamente mercantilizado no sentido capitalista com países em diferentes posições econômicas (GEREFFI; KORZENIEWICZ, 1994). E é sobre esse arcabouço, que não garante o acesso básico à alimentação da população mundial apesar da alta produtividade agronômica, que 
as relações entre agricultura, economia e desenvolvimento devem ser pensadas - desde uma perspectiva sistêmica.

Entretanto, o tema da quantidade de elos na comercialização capitalista exige análises que fujam de uma perspectiva dicotômica. Ao comparar cadeias longas e cadeias curtas, diferentes estudos apontam para as mesmas enquanto resultado de dinâmicas sociais prévias que resultaram na conformação da estrutura mercadológica específica (SWINNEN, 2016; POZO VERGES; VORLEY, 2015; PRITCHARD, 2013). Indicando que o percurso das cadeias é fruto de estruturas sociais anteriores à própria comercialização. Ou seja, pensar canais de circulação de mercadorias, antes de pensar na longitude dos mesmos, deve perpassar quais instituições fundamentam sua existência (SCHNEIDER, 2009).

Ao analisar a sustentabilidade de cadeias de aspargos, Scharwz et al (2016) aponta como a estrutura de circulação do vegetal pautou-se nas políticas desenvolvidas no Peru ao longo da década de 80. Políticas fomentadas tanto pelo poder estatal, como por agências internacionais. Indicando que as longas cadeias que conectam os aspargos peruanos com o mercado europeu (caso analisado pelos autores) não são o fator tensionador e promotor original da problemática, mas as estruturas sociais prévias que moldaram essas práticas (PLEIN, 2010). Casos semelhantes também apontados por Pozo-Vergnes e Vorley (2015) ao analisarem as inserções internacionais das produções agroalimentares em Peru e Senegal, e identificarem a proeminência de políticas nacionais e internacionais na conformação mercadológica capitalista. Retomando as ideias de corn e maiz que, apesar da morfologia semelhante, são frutos de processos institucionais distintos. Biologicamente idênticos, socialmente opostos.

Se a estrutura do mercado capitalista global conforma-se com a centralização econômica e política em polos, com a pulverização da produção de menor valor agregado para periferias (FIORI, 2015; WALLERSTEIN, 2004), as cadeias longas - se operadas na lógica capitalista tornam-se canais de perpetuação de posições produtivas das margens do sistema. Portanto, pensar desenvolvimento humano ${ }^{10}$ perpassa a necessidade de repensar como se estruturam as cadeias de mercado, independentemente do seu tamanho. A questão central não estaria enfocado na quantidade de elos, mas na qualidade sobre a qual os mesmos se pautam que, no presente Regime Alimentar, caracterizam-se por valorizar o fluxo de valor de troca acima do valor de uso (MCMICHAEL, 2016). As contribuições clássicas sobre imperialismo evidenciam como a construção do ambiente social sobre o qual conformam-se as práticas contemporâneas data de

10 Aqui o termo desenvolvimento humano é utilizado em uma perspectiva de Desenvolvimento de Capacidades, conforme proposto por Amartya Sen em "Desenvolvimento como liberdade", de 2012. 
séculos, estando profundamente enraizadas nas culturas locais das diferentes realidades nacionais (LUXEMBURGO, 1976; GRAZZIOTIN, 2019).

$\mathrm{Na}$ contramão desse processo é que alternativas sistêmicas podem ser pensadas, principalmente pautando-se em perspectivas institucionais que valorizem processos democráticos e de maior preservação da biodiversidade. A redução da quantidade de elos desses canais de comercialização seria uma das possibilidades de resultado dessa dinâmica, mas não um fator exclusivo. Quadros distintos poderiam emergir enquanto resultado, como a conformação de cadeias médias (STEVENSON et al, 2011); o estímulo a canais de comercialização regionalizados (MALUF, 2004); formação de mercados imersos (PLOEG, 2016); domesticação das cadeias capitalistas presentes (WRIGHT, 2018); ou ainda processos não explorados tanto pela sociedade civil como pela abordagem acadêmica. Essa latência de novas abordagens se faz essencial em um período de notável crise da estrutura capitalista, cabendo aos processos sociais desenvolvidos no presente a determinação de qual compasso seguirá o sistema econômico pós inflexão - seja sua readaptação ou a extirpação.

É essencial salientar que as alternativas sistêmicas exigem que os diferentes casos nacionais e locais sejam analisados em sua especificidade, a fim de não insistir em dinâmicas generalizantes que atropelem processos regionais. Se o problema pode ser lido de forma abrangente, as soluções devem ser pensadas com pontualidade e entendendo as especificidades das composições sociais (BLOCK; EVANS, 2005).

\section{Considerações e apontamentos finais}

A análise com dados quantitativos é limitada em capturar processos sociais como um todo, ou identificar tendências para além daquelas que os números apresentam. Entretanto, isso não inviabiliza que se façam projeções e levantamentos utilizando dados quantitativos - apenas que se deve reconhecer a especificidade da metodologia utilizada.

Nesse sentido, a visualização das produções agrícolas no século XXI e sua correlação com segurança alimentar dos diferentes países traz informações interessantes. Em relação aos valores agrícolas totais no século XXI, não verifica-se uma relação direta entre alto valor produzido e participação da agricultura no produto interno. Essa proporção é, frequentemente, inversa. Ou seja, países com menor importância da agricultura no PIB apresentando alto valor total. Indicando maior agregação de valor nesses casos.

Em relação a alimentação, países com um alto valor agrícola produzido não apresentaram dados elevados de segurança alimentar. Diversos casos apontaram o contrário: países com alta 
produção agrícola e insegurança alimentar elevada. Da mesma forma, a correlação entre participação da agricultura na composição do produto interno mostrou-se em proporção inversa à garantia nutricional da população do país.

As teorias do Sistema Mundo e dos Regimes Alimentares mostraram-se relacionáveis com o material empírico trabalhado, visto que diferentes segmentações foram identificáveis na análise dos dados nacionais utilizados. Essa aplicabilidade evidencia como a relação entre história, economia e relações internacionais tende a ser compreensível somente através de uma visualização sistêmica, na qual os países não estão distribuídos de forma linear, mas sim em diferentes posições correlacionáveis em uma mesma estrutura.

Como disparadores futuros, a pesquisa ganharia grande contribuição com aprofundamentos em casos específicos que servissem como ilustração dos processos apontados, rompendo com generalismos utilizados. Contribuindo tanto para problematização dos dados quantitativos como para ampliação da leitura sistêmica.

\section{Referências bibliográficas}

ALMEIDA FILHO, N.; PAULANI, L.. M. Regulação social e acumulação por espoliação. Economia e Sociedade, v. 20, n. 2, 2011.

ARRIGHI, G.. O longo século XX. Contraponto: São Paulo, 1996.

BERSteIn, H.. Notes on Capital and Peasantry. Rev. of Afr. Pol. Eco., v. 4, 60-73, 1977.

BLOCK, F.; EVANS, P.. The State and the Economy. In: SMELSER, N.; SWEDBERG, R. (Eds.). Handbook of Economic Sociology. Princeton, pp. 505 - 526, 2005.

BRAUDEL, F.. A dinâmica do capitalismo. Editora Rocco: Rio de Janeiro, 1987.

BRESSER PEREIRA, L. C.. Desenvolvimento, progresso e crescimento econômico. Revista de Cultura e Política, v. 93, 2014.

CHANG, H. J.. Chutando a escada. UNESP: São Paulo, 2004.

COHEN, B. J.. The Question of Imperialism. London: Palgrave Macmillan UK, 1973.

FARIA, L. A.. Capitalismo, espaço e tempo. Ensaios FEE, v. 20, n. 1, 1999.

FEIJÓ, C.; OREIRO, J. L.. Desindustrialização: Conceituação, causas, efeitos e o caso brasileiro. Revista de Economia Política, v. 30, n. 2, 2010.

FIORI, J. L.. História, Estratégia e Desenvolvimento. Boitempo: São Paulo, 2015. 
FRIEDMANN, H.. Simple Commodity Production and Wage Labour in the American Plains. Journal of Peasant Studies, v. 6, n. 1, 1978.

FRIEDMANN, H.. Remaking Traditions: How We Eat, What We Eat and the Changing Political Economy of Food. In: BARNDT, Deborah (ed.). Women Working the NAFTA Food Chain: Women, Food, and Globalization. Toronto: Second Story, pp. 35-60, 1999.

GEREFFI, G.; HUMPHREY, J.; STURGEON, T.. The Governance of Global Value Chains. Review of International Political Economy, v. 12, n. 1, 2005.

GEREFFI, G.; KORZENIEWICZ, M. (Eds.). Commodity chains and global capitalism. Praeger, Westport, 1994.

GEREFFI, G.; LEE, J.. Why the World Suddenly Cares About Global Supply Chains. Journal Supply Chain Management, v. 48, pp. 24-32, 2012.

GRAZZIOTIN, H.. O processo histórico de formação do sistema-mundo capitalista e a sua dinâmica. Economia Ensaios, v. 34, n. 1, 2019.

HUANG, P. C. C.. China's New Age Small Farming and their vertical integration: agrobusiness or co-ops?. Modern China, v. 37, pp. 107-135, 2011.

KAUTSKY, K.. Imperialism and the war In: Die Neue Zeit, 1914. Disponível em: http://marxists.org/archive/kautsky/1914/09/war.htm. (acesso em 09/04/2021).

LUXEMBURGO, R.; BUKHARINE, N.. Imperialismo e acumulação de capital. Edições 70: Rio de Janeiro, 1976.

LUXEMBURGO, R.. A acumulação de capital. Zahar: Rio de Janeiro, 1976.

MALUF, R. S.. Mercados agroalimentares e a agricultura familiar no Brasil: agregação de valor, cadeias integradas e circuitos regionais. Ensaios FEE nº 25, pp. 299-322, 2004.

MARINHO, P. L.. Explicações sobre a internacionalização produtiva das empresas: Das teorias clássicas às novas teorias. Tese de Doutorado em Desenvolvimento Econômico, Universidade Federal do Paraná, Brasil, 2013.

MARRADI, A.. Classification, typology, taxonomy. Qual. And Quant. v. 24, 129-157, 1990.

MCMICHAEL, P.. A food regime genealogy. Journal of Peasants Studies, v. 36, 2009.

MCMICHAEL, P.. Regimes Alimentares e Questões Agrárias. UFRGS: Porto Alegre, 2016.

MICHELENA, J. A.. Crise no Sistema Mundial. Paz e Terra: São Paulo, 1977.

PEREIRA, V. V.. As primeiras preocupações com a periferia do sistema capitalista nas teses do imperialismo de Kautsky e Bukharin. Nova Economia, v. 27, n. 2, 2017.

PLEIN, C.. Capitalismo, agricultura familiar e mercantilização. Gepec, v. 14, 96-111, 2010. 
PLOEG, J. D.. Mercados aninhados recém criados. In: MARQUES, F. C.; CONTERATO, M. A.; SCHNEIDER, S. (orgs.). Construção de mercados e Agricultura familiar: desafios para o desenvolvimento rural. UFRGS: Porto Alegre, pp. 21 - 52, 2016.

POZO-VERGNES, E.; VORLEY, B.. Global or local food chains? Uncovering the dilemmas in Senegal and Peru. Issue Paper - Food and Agriculture. IIED, Londres, 2015.

PRITCHARD, B.. Food Chains. In: MURCOTT, A.; BELASCO, W.; JACKSON, P. The Handbook of Food Research. Bloomsburry, Londres, pp. 167 - 176, 2013.

SCHNEIDER, M.. Developing the Meat Grab. Journal of Peasant Studies, v. 41, n. 4, 2014.

SCHNEIDER, S.; SCHUBERT, M. N.; ESCHER, F.. Regimes Agroalimentares e o lugar da agricultura familiar - uma apresentação ao debate. Mundi Meio Amb. e Agr., v. 1, n. 1, 2016.

SCHNEIDER, B. R.. Hierarchical market economies and varieties of capitalism in Latin America. Journal of Latin American Studies, n. 41, v. 3, pp. 553-575, 2009.

SCHWARZ, J.; SCHUSTER, M.; ANNAERT, B.; MAERTENS, M.; MATHIJS, E.. Sustainability of Global and Local Food Value Chains: An Empirical Comparison of Peruvian and Belgian Asparagus. Sustainability, v. 8, 2016.

STEVENSON, G. W.; CLANCY, K.; KING, R.; LEV. L.; OSTROM, M.; SMITH, S.. Midscale Food Value Chains: An Introduction. Journal of Agriculture, Food Systems, and Community Development, v. 8, n. 4, 2011.

SWINNEN, J.. Value chains, agricultural markets and food security, The State of Agricultural Commodity Markets 2015-16. FAO. 2016.

VISENTINI, P. F.; RIBEIRO, L. D. T.; PEREIRA, A. D.. História da África e dos Africanos. Editora Vozes: Rio de Janeiro, 2012.

WALlERSTEIN, I.. The Concept of National Development (1917 - 1989). The American Behavioral Scientist, 1992.

WALLERSTEIN, I.. Análises del Sistema Mundo: una introduccion. Siglo XXI, 2004.

WRIGHT, E. O.. Como ser anti-capitalista no século XXI?. Boitempo: São Paulo, 2017.

WOOD, E.. O império do capital. Editora Boitempo: São Paulo, 2015. 